\title{
CRENÇAS NO ENSINO-APRENDIZAGEM DE IDIOMAS: O GRUPO FOCAL COMO INSTRUMENTO DE PRODUÇÃO DE DADOS
}

\author{
Luciana Kinoshita*
}

RESUMO: O assunto em investigação é o grupo focal como ferramenta de produção de dados em estudos sobre crenças no ensino-aprendizagem de línguas estrangeiras. Nossa intenção é auxiliar no planejamento e aplicação de grupos focais que tratem sobre esse tema. Realizamos estudo bibliográfico e relato de nossa própria experiência em planejar e aplicar o instrumento. O referencial teórico incluiu Barbosa (2012), Backes et al (2011), Kinoshita (2018), Morgan (2013), Santos, Silva e Jesus (2016), Teixeira e Maciel (2009), Trad (2009), entre outros. Resultados indicam que o uso do grupo focal é apropriado para produzir dados sobre crenças a respeito do ensino-aprendizagem de idiomas, contanto que haja planejamento e preparação do pesquisador de maneira antecipada e adequada.

PALAVRAS-CHAVE: Crenças; Ensino-aprendizagem de idiomas; Grupo focal.

\section{Considerações introdutórias}

As crenças fazem parte do processo de ensinar-aprender qualquer língua estrangeira (LE). Elas são representações que envolvidos no ensino-aprendizagem (EA) de idiomas possuem sobre o processo de ensinar/aprender uma nova LE ou sobre outros fatores (ex.: estereótipos, contexto social, cultura etc.) que possam influenciar nele positiva ou negativamente. Tratam-se de representações que podem ser compartilhadas, mantidas, construídas e reconstruídas entre/pelos sujeitos ao longo da vida, antes do início do transcurso de processo de ensinar-aprender e/ou após o seu término.

O objetivo da investigação é auxiliar no planejamento e aplicação de grupos focais sobre crenças no EA de idiomas, com o intuito de que esse texto possa servir de guia para interessados que pretendam usar o grupo focal em suas próprias pesquisas sobre o mesmo tema.

* Professora da Universidade Federal do Sul e Sudeste do Pará (Unifesspa). Doutora em Educação pela Universidade se São Paulo (Usp).Fez doutorado sanduíche na Siauliai University, na Lituânia. 
Em nosso estudo utilizamos a pesquisa bibliográfica e o relato de experiência de uso de grupos focais com graduandos de um curso de Letras Inglês. Trabalho que foi desenvolvido como nossa tese de doutoramento pela Faculdade de Educação da Universidade de São Paulo (USP) e tratava sobre as crenças a respeito de ensinar-aprender inglês como LE durante a licenciatura.

Pretendemos responder às seguintes questões:

- Quais as vantagens de usar grupo focal em pesquisas sobre crenças?

- Quais as desvantagens de usar grupo focal em pesquisas sobre crenças?

- Como planejar um grupo focal para desenvolver uma pesquisa sobre crenças?

- Como aplicar um grupo focal para desenvolver uma pesquisa sobre crenças?

Segmentamos o texto em seis partes. A primeira delas é a presente seção introdutória seguida de outras que tratam sobre definição de conceitos, aspectos pertinentes ao instrumento (suas vantagens e desvantagens), planejamento, aplicação e considerações finais, além de uma lista com as referências utilizadas.

\section{Definições de grupo focal}

Escolhemos o grupo focal como um meio a partir do qual produzimos dados da então população-amostra formada por graduandos de um curso de licenciatura em Letras Inglês, tanto calouros quanto concluintes. Nós o escolhemos porque:

A técnica do grupo focal para coleta de dados é indicada para estudos que buscam compreender atitudes, preferências, necessidades, sentimentos, representações, ou seja, pontos de vista sobre uma temática, ou mesmo quando se quer entender em profundidade um comportamento dentro de um grupo determinado. (BARBOSA, 2012, p. 40)

Desta maneira, consideramo-lo adequado para trabalhar com crenças dos sujeitos de nossa pesquisa. Ele mostra-se ainda ideal para ser utilizado após a aplicação de um questionário por, segundo Dias (2000, p. 7), “dar oportunidade aos participantes de exporem aberta e detalhadamente seus pontos de vista, é capaz de trazer à tona respostas mais com- 
pletas, permitindo ao pesquisador conhecer melhor e mais profundamente o grupo pesquisado”. Assim, ao realizar o grupo focal após a aplicação dos questionários, como fizemos, temos a possibilidade de não apenas melhor compreender as crenças já produzidas por meio do primeiro instrumento, mas também de observar as novas que vierem a ser expostas.

Diversos autores já conceituaram e caracterizaram esta ferramenta, como podemos verificar no quadro a seguir:

Quadro 1 - Diferentes conceitos de grupo focal

\begin{tabular}{|l|}
\hline \multicolumn{1}{|c|}{ Definições } \\
\hline $\begin{array}{l}\text { "[...] o grupo focal representa uma técnica de coleta de dados que, a partir da interação grupal, promove uma } \\
\text { ampla problematização sobre um tema ou foco específico". (BACKES et al, 2011, p. 438) }\end{array}$ \\
\hline "Um grupo focal (GF) é um grupo de discussão informal e de tamanho reduzido, com o propósito de obter \\
informações de caráter qualitativo em profundidade". (GOMES; BARBOSA, 1999, p. 1) \\
\hline "Grupos focais são uma forma de entrevista em grupo". (GIBBS, 1997: tradução nossa) \\
\hline $\begin{array}{l}\text { "[...] o grupo focal como um procedimento de coleta de dados no qual o pesquisador tem a possibilidade de } \\
\text { ouvir vários sujeitos ao mesmo tempo, além de observar as interações características do processo grupal". } \\
\text { (KIND, 2004, p. 126) } \\
\text { "Um grupo focal é uma discussão cuidadosamente planejada destinada a obter as percepções sobre uma área } \\
\text { de interesse definida de um grupo de indivíduos selecionados". (MASI, s/d: tradução nossa) }\end{array}$ \\
\hline $\begin{array}{l}\text { [...] grupo de foco é uma modalidade de entrevista, estabelecida de acordo com um roteiro que tem o propó- } \\
\text { sito de atingir os objetivos pretendidos pelo pesquisador. (OLIVEIRA; LEITE; RODRIGUES, 2007, p. 4) }\end{array}$ \\
\hline $\begin{array}{l}\text { Grupo focal é uma técnica de pesquisa formulada especialmente numa abordagem qualitativa, não diretiva, } \\
\text { que coleta e analisa dados por meio das interações pessoais em forma de grupos que, ao discutirem sobre } \\
\text { um determinado tema em comum, sugerido pelo pesquisador, permite aos entrevistados exporem suas ideias } \\
\text { e estabelecerem opiniões sobre o tema pesquisado, possibilitando o aprofundamento do tema, ou a desco- } \\
\text { berta de algo que esteja sendo objeto de investigação; dependerá apenas do objetivo principal da pesquisa. } \\
\text { (SANTOS; SILVA; JESUS, 2016) }\end{array}$ \\
\hline
\end{tabular}

Fonte: Próprio autor

No quadro há sete conceitos de teóricos provenientes de diferentes áreas que utilizam o grupo focal como instrumento, como é o caso de Administração (OLIVEIRA; LEITE; RODRIGUES, 2007), Educação (GOMES; BARBOSA, 1999; SANTOS; SILVA; JESUS, 2016), Saúde (BACKES et al, 2011), Sociologia (GIBBS, 1997), Marketing (MASI, s/d) e Psicologia (KIND, 2004). Não existe, dentre as definições expostas, qualquer que

\footnotetext{
1 Texto original: "Focus groups are a form of group interviewing". (GIBBS, 1997).

2 Texto original: "A focus group is a carefully planned discussion designed to obtain a selected group of individuals' perceptions regarding a defined area of interest'. (MASI, s/d) 
esteja mais ou menos correta, cada uma, de forma diferente, adequa-se à sua área de conhecimento e especificidades da investigação em que foi empregada.

Temos, então, formulações mais simples e diretas a exemplo da de Gibbs (1997), enquanto outras são mais detalhadas como as de Oliveira, Leite e Rodrigues (2007) e de Santos, Silva e Jesus (2016). E, partindo do que cada uma delas expressa e pode ser relacionado ao grupo focal que utilizamos no estudo de crenças em ensino-aprendizagem de idiomas, construímos o nosso próprio conceito para o instrumento.

Para nós, o grupo focal é um procedimento de coleta de dados em que acontece uma discussão grupal planejada e estabelecida de acordo com um roteiro por meio do qual os sujeitos discutem sobre um determinado assunto em comum problematizando-o e, a partir desta interação, é possível observar representações dos indivíduos geradas pela exposição de ideias e opiniões sobre questões específicas que podem levar ao aprofundamento da compreensão do que já é conhecido sobre o assunto ou à descoberta de algo novo sobre o que está sendo estudado.

\section{Aspectos pertinentes ao instrumento}

Expomos aqui as vantagens e limites do grupo focal como instrumento de produção de dados. A seção está dividida em duas partes e é destinada a fazer considerações, primeiramente, sobre as vantagens e, após, sobre as desvantagens em utilizar o procedimento em questão.

\section{Vantagens do grupo focal}

Há inúmeras vantagens em utilizar o grupo focal para produzir dados. Vamos expor algumas delas. O International Training and Education Center for Health (I-TECH) 3 aponta quatro:

- Revela uma variedade de opiniões sobre um determinado tópico.

- Ajuda a esclarecer ou validar informação recolhida através de entrevistas individuais, pesquisa ou outros métodos de recolha de dados. 
- Pode conduzir à [sic] novas informações importantes tanto para os facilitadores quanto para o grupo de participantes.

- É agradável para os participantes. (I-TECH, 2008, p. 2)

Que, por sua vez, podem ser complementadas por mais vantagens apontadas:

- Baixo custo

- Fornece resultados rápidos

- Formato flexível, permitindo que o moderador explore perguntas não previstas e incentive a interação entre os participantes

- Eficientes para obter informações qualitativas

- Eficiente para esclarecer questões complexas no desenvolvimento de projetos

- Adequado para medir o grau de satisfação das pessoas envolvidas. (GOMES; BARBOSA, 1999, p. 7)

Vamos discorrer sobre cada um desses pontos. O grupo focal revela uma variedade

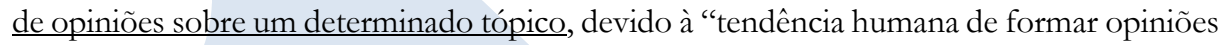
e atitudes na interação com outros sujeitos” (BACKES et al, 2011, p. 439). A quantidade de informações e dados produzidos, durante uma situação de comunicação estabelecida entre vários sujeitos, costuma ser maior do que em entrevistas individuais.

A ajuda a esclarecer ou validar informação recolhida através de entrevistas individuais, pesquisa ou outros métodos de recolha de dados era uma característica necessária em nossa investigação, uma vez que estávamos utilizando o grupo focal como continuidade aos questionários que aplicamos anteriormente com os mesmos sujeitos. Por isso, "O tempo do grupo será aproveitado para o debate de questões mais complexas, cuja apreensão seria mais limitada através, por exemplo, de questionários”. (TRAD, 2009, p. 788).

O uso deste procedimento pode conduzir a novas informações importantes tanto para os facilitadores quanto para o grupo de participantes. Isso acontece porque "o participante é convocado a emitir opiniões sobre assuntos que talvez nunca tenha refletido anteriormente” (BACKES et al, 2011, p. 439). Nem todas as crenças estão no nível do consciente e as discussões provocadas em grupo podem ajudar os sujeitos não apenas a descobri-las, mas também a encontrar espaço para expressá-las.

O grupo focal é pensado para ser agradável para os participantes. Para que, como dissemos no parágrafo anterior, eles tenham um lugar para expor suas crenças, falar sobre 
o que pensam a respeito dos assuntos em questão. A agradabilidade é garantida incluindo a preparação do ambiente para a realização da atividade, no que diz respeito a climatização, conforto etc., (OLIVEIRA; LEITE; RODRIGUES, 2007), bem como a garantia de liberdade de expressão que leva a uma participação efetiva (ZIMMERMANN; MARTINS, 2008).

Ele também tem baixo custo para ser aplicado. Para Morgan (2013), os custos de usar um grupo focal para investigações próprias é significativamente menor do que o uso do mesmo procedimento em pesquisas de mercado encomendadas por empresas, por exemplo. No nosso caso, a vantagem do baixo custo não necessariamente se aplicava porque não havia despesas com o que se costuma precisar investir como "[...] salários para moderadores, viagens a locais de pesquisa, aluguel de sites de pesquisa, pagamentos a participantes e produção e transcrição de fitas" (MORGAN, 2013, p. 32: tradução nossa)4, haja vista que todo o trabalho foi desenvolvido por nós mesmos, quando estávamos residindo no mesmo município onde realizamos o estudo em campo.

O fato de fornecer resultados rápidos é também apontado por Morgan (1997) como um benefício que, de acordo com o autor, é devido à habilidade que o grupo focal tem de concentrar os dados em um tópico de interesse preciso, fazendo com que as informações produzidas sejam direcionadas ao que especificamente interessa ao pesquisador. Diferente do que ocorre, por exemplo, em observações participantes, em que há uma gama maior de elementos a serem observados para então selecionar o necessário.

O formato flexível também é uma característica em destaque. A flexibilidade “[...] permite que o mediador explore dados inicialmente não previstos, que vão surgindo no desenrolar da conversa” (TEIXEIRA; MACIEL, 2009). Isso proporciona a oportunidade de explorar perguntas não previstas e incentivar a interação entre os participantes de maneiras diversas.

${ }^{4}$ Texto original: "[...] salaries to moderators, travel to research sites, rental of research sites, payments to participants, and producing and transcribing tapes". (MORGAN, 2013, p. 32). 
Grupos focais são eficientes para obter informações qualitativas. Em nosso estudo, adotamos uma abordagem tanto qualitativa quanto quantitativa por acreditar que ele comportava mais de uma forma de abordá-lo. A maior parte dos dados que necessitavam ser gerados quantitativamente foram produzidos por meio do questionário. Logo, a utilização de um instrumento cuja eficiência está mais voltada para o tratamento qualitativo de dados mostrava-se ideal, pois, ainda que não fossem apenas dados qualitativos que surgissem naquele momento, havia mais probabilidade de que eles seriam a maioria.

Outra vantagem é que eles são eficientes para esclarecer questões complexas no desenvolvimento de projetos. A aprendizagem de uma língua é um fenômeno complexo, pois é cognitivo e não apenas linguístico (PAIVA, 2002). Por conseguinte, aspectos presentes nestes processos de E/A carregam características de complexidade 5 , como é o caso das crenças. Crenças são dinâmicas, emergentes, socialmente construídas e situadas contextualmente, experienciais, mediadas, paradoxais e contraditórias, relacionadas à ação de uma maneira indireta e complexa, e não tão facilmente distintas do conhecimento (BARCELOS, 2007).

Por fim, grupos focais são adequados para medir o grau de satisfação das pessoas envolvidas. A satisfação e a frustração em relação ao processo de EA de um idioma estão diretamente ligados ao quão motivado o sujeito está para dar continuidade ao seu processo de aprendizagem que nunca terá fim. Dörnyei (2014, p. 519: tradução nossa) lembra que a "motivação é responsável por que as pessoas decidem fazer algo, quanto tempo elas estão dispostas a sustentar a atividade, e com quanto empenho elas vão buscá-lo"6 [grifos do autor], daí a necessidade de que tivéssemos acesso a dados que nos levassem a melhor compreender o relacionamento entre motivação, cognição e emoção dos sujeitos.

\footnotetext{
${ }^{5}$ A primeira autora a relacionar a complexidade à aprendizagem de idiomas foi Larsen-Freeman (1997) ao apontar semelhanças entre a ciência do caos/complexidade e a aquisição de uma segunda língua, como a dinamicidade, complexidade e não linearidade.

${ }^{6}$ Texto original: "Motivation is responsible for why people decide to do something, bow long they are willing to sustain the activity, and how hard they are going to pursue it”. (DÖRNYEI, 2014, p. 519)
} 


\section{Limites do grupo focal}

Há desvantagens em usar qualquer procedimento ou instrumento para produção de dados e, no caso do grupo focal, não é diferente. Dedicamos a presente seção a expor algumas das limitações e como contornamos cada uma delas.

Gomes e Barbosa apontam oito limites:

- Formato flexível torna susceptível à maneira de ser do moderador

- Não fornece dados quantitativos

- Informações obtidas não podem ser generalizadas e podem ser difíceis de serem analisadas

- Não garante total anonimato

- Exige facilitador/moderador com experiência em conduzir grupos

- Depende da seleção criteriosa dos participantes

- As discussões podem ser desviadas ou dominadas por poucas pessoas

- Comentários devem ser interpretados no contexto do grupo.

(GOMES; BARBOSA, 1999, p. 7)

Acrescentamos a eles mais alguns outros:

- Apresenta um desafio logístico;

- Exige um moderador habilidoso;

- Tem menos controle sobre a coleta de dados. (MASI, s/d)

Diante de tantas desvantagens, é necessário atentar para que elas não superem as qualidades que apontamos no item anterior. Para tanto, vejamos o que consideramos necessário fazer para que isso não acontecesse.

Mencionamos a flexibilidade como uma das vantagens, mas o formato flexível torna susceptível à maneira de ser do moderador. Realmente é uma possibilidade, porém, para evitar isso, elaboramos o que Trad (2009) chama de roteiro de questões ou, de acordo com Kind (2004), um temário ou guia de temas, composto por perguntas, como propostas por Villard (2003), abertas e flexíveis com foco no tópico de pesquisa, incluindo ainda sugestões de perguntas investigatórias para ajudar os sujeitos a compreender melhor o que cada questionamento quer dizer. A partir de um planejamento prévio de qualidade podemos diminuir a influência subjetiva do moderador durante o grupo focal. 
O fato de ser um procedimento que não fornece dados quantitativos, ou melhor, que não é indicado para este uso, não foi um problema em nossa investigação, uma vez que anteriormente aplicamos outro instrumento (questionário) que servia para esse fim e, por meio dele, produzimos os dados quantitativos dos quais precisávamos.

Vamos dividir a terceira desvantagem apontada por Gomes e Barbosa (1999) em duas, pois ela inclui dois limites distintos em um único tópico. Em relação à primeira parte (informações obtidas não podem ser generalizadas), concordamos com I-TECH (2008), para quem, os resultados fornecidos por grupos focais não devem ser generalizados, pois não é possível atribuir que crenças e opiniões observadas por meio deles a toda uma população. Entretanto, em nosso estudo, a intenção não era que tal atribuição ocorresse, mas compreender as crenças expressadas pelos participantes, sem necessariamente esperar que elas possam ser aplicáveis a todos.

Já, na segunda parte, temos a circunstância de que as informações podem ser difíceis de serem analisadas, o que é algo comum quando os dados produzidos são essencialmente qualitativos, como durante o uso do grupo focal. Contudo, atualmente existem softwares de apoio à análise qualitativa, como o QSR NVIVO 2.0 e o WebQDA, que são programas que ajudam a dividir o texto em seguimentos, colocar codificações, encontrar/apresentar trechos em categorias ou combinação de categorias, entre outras tarefas. Dicicco-Bloom e Crabtree (2006) lembram que estes programas não analisam dados, mas podem ser uma grande ajuda no manejo e no processo de análise.

Outra questão é que não garante total anonimato. Backes et al (2011, p. 440) enfatiza que "é importante que o ambiente dos encontros seja acolhedor e assegure privacidade para facilitar o debate e aprofundar as discussões", porém, ainda que isso seja garantido, como trata-se de um tipo de entrevista coletiva, não há anonimato entre os participantes de cada grupo, o que poderia gerar algum grau de intimidação dificultando uma interação natural entre eles. Para diminuir essa possibilidade, decidimos conversar com alunos de turmas diferentes separadamente, a fim de que assim, não houvesse diferenças hierárquicas entre os sujeitos que viessem a causar prováveis intimidações ou desconfortos. 
Discorramos conjuntamente sobre as limitações a exigência de facilitador/moderador com experiência em conduzir grupos e a exigência de um moderador habilidoso, pois elas se complementam. De acordo com Santos, Silva e Jesus (2016), em entrevistas grupais, o entrevistador assume o papel de moderador entre os participantes, para tanto, ele precisa estimulá-los a falar e reagir ao que é dito pelos presentes, valendo-se da criatividade e capacidade de argumentação. Para desempenhar adequadamente esta função, seguimos a recomendação de Teixeira e Maciel (2009) que indicam que o mediador deve contar com um roteiro de questões preparadas antecipadamente segundo os objetivos e dados a produzir e também "devem ser explicados os objetivos do encontro, a forma de registro, a anuência dos participantes, a garantia de sigilo dos registros e dos nomes" (SILVA; ASSIS, 2010, p. 150).

Grupos focais dependem da seleção criteriosa dos participantes. Todavia, esta não é uma desvantagem que se aplicava à nossa investigação, pois, em geral, os sujeitos tinham características bastante homogêneas. Então, não havia como diferenciá-los muito entre si. Logo, todos eram convidados a participar sem que isso viesse a influenciar significativamente nos resultados.

Existe a possibilidade de as discussões serem desviadas ou dominadas por poucas pessoas e, para se resguardar disso, cabe ao mediador a preocupação em controlar o tempo e os debates, dificultando o afastamento dos objetivos da conversa e o monopólio do turno de fala por alguns sujeitos (TEIXEIRA; MACIEL, 2009), podendo ainda levar os indivíduos mais extrovertidos a envolver e estimular os demais (BACKES et al, 2011) a participarem mais ativamente dos debates.

Embora Gomes e Barbosa (1999) apontem que comentários devem ser interpreta-

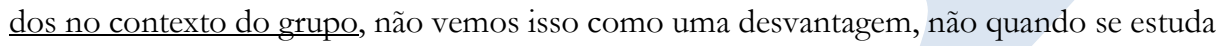
crenças, visto que elas precisam de contexto para serem compreendidas (BARCELOS, 2001).

A inconveniência de apresentar um desafio logístico é comum a procedimentos de produção de dados em grupo, visto que é complicado coordenar agendas de diferentes participantes e selecionar um espaço que seja acessível a todos e ainda garanta a privacidade. 
Por isso, utilizamos um lugar (a instituição onde os alunos estudam) em data e horário (período de aulas) que os estudantes estivessem juntos, para que fosse viável a participação de todos que assim o desejassem.

Ter menos controle sobre a coleta de dados é uma desvantagem, conforme Gomes e Barbosa (1999). Para eles, ter menos controle ao produzir os dados por os participantes moldarem a discussão é um aspecto negativo, mas, na condição do nosso estudo, isso acabou sendo não apenas positivo, mas necessário, haja vista que estávamos lidando com algo que, de acordo com Pajares (1992), está além do controle individual ou conhecimento. Assim como não é possível controlar no que se acredita ou espera em relação a algo, crenças não são controláveis, da mesma maneira, também não conseguimos monitorar, de forma excessivamente limitada, a produção de dados que as envolvem. Portanto, ainda que utilizássemos um procedimento diferente do grupo focal que nos garantisse maior controle, o fato de estarmos trabalhando com crenças não nos asseguraria isso.

Expusemos aqui algumas das limitações de uso do grupo focal e como pensamos em contornar cada uma delas para tornar a utilização do procedimento mais exequível na investigação que desenvolvemos.

\section{Planejamento de grupo focal}

A fase de planejamento é essencial para que o grupo focal funcione devidamente. Nela pode-se prever problemas e antecipar possíveis soluções. Em nossa pesquisa, dedicamos esse período a elaborar três documentos que seriam utilizados na condução das entrevistas em grupo:

- Termo de Consentimento Livre e Esclarecido (TCLE);

- Guia de condução de sessão;

- Temário ou guia de temas.

Vejamos um pouco mais sobre cada um deles. É necessário que todos os envolvidos no estudo (instituição, sujeitos e auxiliar de pesquisa) autorizem a sua participação nele. Daí a necessidade de ter mais de mais de uma versão do TCLE. 
Esclarecemos que não criamos nenhum TCLE especificamente voltado para a instituição solicitando autorização para a realização dos grupos focais, porque optamos por fazer apenas um único TCLE contendo nosso pedido de anuência para a realização da pesquisa de campo como um todo, que incluiu questionários, grupos focais e entrevistas. Este TCLE foi assinado pelo professor responsável pela coordenação do curso na época.

Apenas dois TCLE foram elaborados de forma exclusiva para os grupos focais, ambos direcionados para aqueles que estariam presentes durante a sua condução: auxiliar de pesquisa e alunos.

Para construí-los, utilizamos como base os modelos propostos por Barbosa (2012), Zimmermann e Martins (2008), bem como o TCLE sugerido pelo Comitê de Ética na Pesquisa da Faculdade de Educação da Universidade de São Paulo (FEUSP).

O conteúdo de ambos os TCLE listados acima é semelhante e os utilizamos para preparar o nosso que continha:

- Tema e objetivo geral da pesquisa;

- Nomes e contatos (e-mail e telefone) da pesquisadora e de seu orientador;

- Explanação sobre a garantia de anonimato e privacidade dos participantes;

- Orientações a respeito de como proceder caso não deseje mais participar do estudo;

- Esclarecimento de que a participação não implica qualquer compensação financeira;

- Declaração de que aceita participar;

- Local e data;

- Nome e assinatura da pesquisadora.

Há apenas duas diferenças entre eles. A primeira é a questão do nome e da assinatura, como são TCLE elaborados para indivíduos diferentes, consequentemente este aspecto também diverge. Logo, no TCLE do(a) auxiliar de pesquisa, ao final da página ele(a) escreve o seu nome e assina. Enquanto, no dos alunos, todos os que estão participando da mesma sessão de grupo focal, escrevem seu nome e assinam no verso da folha, onde também podem, se assim o desejarem, preencher o espaço destinado ao seu telefone e/ou e- 
mail. A outra diferença está no segundo parágrafo do texto do TCLE, que contém a descrição do que consiste a participação dos sujeitos. Portanto, temos:

a) Para o(a) auxiliar: operar recursos multimídia para gravações em áudio e vídeo dos grupos focais com os sujeitos da referida pesquisa.

b) Para os alunos: conceder entrevista(s) em forma de grupo focal à pesquisadora sobre o tema da investigação em questão. A(s) entrevista(s) é(são) coletiva(s) e gravada(s) em áudio e vídeo.

Todos os participantes receberam uma via do TCLE assinado e datado pela pesquisadora, sendo, portanto, necessário providenciar antecipadamente impressões e cópias suficientes para todos os entrevistados em cada sessão.

Criamos o guia de condução de sessão baseando-nos no modelo proposto por Zimmermann e Martins (2008). Ele é um roteiro para embasar o andamento das sessões de grupo focal cujo conteúdo dividimos em oito partes/momentos:

a) Organização do ambiente;

b) Acolhimento dos sujeitos;

c) Explanação sobre a técnica;

d) Leitura e assinatura do TCLE;

e) Apresentação dos participantes;

f) Discussão;

g) Síntese;

h) Lista de materiais e recursos.

O guia é um planejamento de como pretendemos conduzir a sessão. Ainda que seja possível aplicar o grupo focal sem utilizá-lo, não é uma prática aconselhável. Recomendamos fazer um nem que seja em forma de esboço, principalmente quando o entrevistador for inexperiente e/ou mais de uma sessão for ser realizada, pois isso garante a organização, a padronização e (em certa medida) evita surpresas e esquecimentos. Podemos dizer que a importância de um guia de condução é equivalente à de um plano de aula.

Para construir o temário ou guia de temas, tomamos como base o de Kind (2004). O nosso foi composto de uma lista de 31 perguntas. Elas eram as mesmas tanto para a 
turma de calouros quanto para a de concluintes, visando otimizar o processo de compilação e análise de dados. A listagem, por sua vez, estava dividida em seis temas sobre os quais versam as questões:
a) Aprendiz de inglês;
b) Professor de inglês;
c) Formador de professor de inglês;
d) Ensino/Aprendizagem na licenciatura;
e) Grade curricular;
f) Aplicar Teoria à prática.

Pensamos os temas e as perguntas à luz do referencial teórico que compunha o nosso estudo, também visando confirmar e/ou melhor compreender dados produzidos nos questionários. Quando o grupo focal é realizado após uma coleta de dados inicial, como foi o nosso caso em que os questionários foram aplicados antes, sugerimos sempre levar em consideração o que foi perguntado e respondido anteriormente para assim julgar o que já foi suficientemente explorado e o que ainda precisa ser melhor trabalhado. Para tanto, é preciso ter, no mínimo, uma análise prévia dos dados.

Como os grupos focais visam produzir dados essencialmente qualitativos, o ideal é que as perguntas sejam abertas e sobre temas que gerem espaço para discussão. Elaborar questões sobre crenças é uma tarefa delicada e trabalhosa, pois é necessário evitar, ao máximo, que a própria pergunta venha a influenciar na resposta (ou até mesmo modificar a crença) do sujeito. Nesse sentido, quanto mais simples e direta a questão, melhor efeito ela terá.

No caso de grupos focais, não há problema se algum participante vier a modificar a sua crença com base na resposta de outro entrevistado, o que não deve acontecer é que as perguntas do entrevistador exerçam influência nisso. Daí a necessidade de um cuidadoso trabalho de planejamento prévio e, preferencialmente, também revisão feita por um segundo pesquisador. Lógico que é quase impossível que o entrevistador interaja com os participantes e mantenha-se completamente neutro (um simples gesto ou olhar pode trazer indícios de uma crença sua), mas, ao pesquisar crenças, é necessário estar atento a isso. 
Escolher e testar recursos de gravação em áudio e vídeo também é preciso na fase de planejamento. Como se trata de uma entrevista em grupo, é aconselhável que a principal gravação seja feita em vídeo para que seja viável identificar cada participante em seu turno de fala, facilitando assim a transcrição dos dados. Sugerimos que a gravação em áudio seja utilizada somente como apoio e que, se possível, o vídeo seja gravado por mais de um recurso ao mesmo tempo, por exemplo, computador e celular, garantindo que a gravação realmente aconteça sem falhas. As alternativas de recursos para gravação hoje em dia são várias (ex.: câmera, celular, computador, tablet etc.). Recomendamos que a opção se dê por aquele que quem o operará tenha mais familiaridade e facilidade de manusear, podendo também se capacitar ainda mais com vídeos e tutoriais disponíveis na internet. É imprescindível testar antecipadamente todos os recursos que serão utilizados para gravar, verificar se há espaço ou memória suficiente em cada um deles para salvar as gravações, certificarse que cabos, extensões, adaptadores e outros materiais necessários estão adequadamente funcionando e disponíveis para usar no dia, além de carregar os dispositivos que funcionam à bateria.

É preciso ainda determinar a quantidade de participantes por sessão. Em nosso estudo escolhemos trabalhar com seis alunos por vez. Definimos essa porção com base em Backles et al (2011, p. 40) que sugere que "o número de participantes esteja situado em um intervalo entre seis e quinze" e em Aschidamini e Saupe (2004, p. 11), que acreditam que "o tamanho do grupo [deve] estar adaptado aos propósitos da tarefa" e "se o que se pretende é alcançar a profundidade de expressão de cada participante, um grupo pequeno seria mais indicado" (BACKES et al, 2011, p. 40). Por isso, decidimos usar um número próximo da menor quantidade de indivíduos sugerida, porque, para nós, era relevante que os dados produzidos expressassem crenças do modo mais profundo possível. Portanto, um baixo número de sujeitos nos era ideal para permitir que todos tivessem tempo e espaço suficientes para externar suas representações sobre o tema.

Como nossa população-amostra era pequena (40 pessoas), inicialmente pensamos em fazer apenas duas sessões: uma com a turma de calouros e outra com a de concluintes. Ainda que definir a quantidade de sessões de antemão seja importante, é preciso que o 
pesquisador esteja atento para perceber a necessidade de mudanças, que foi o que aconteceu em nossa investigação. A quantidade de sessões realizadas com cada grupo acabou sendo diferente por duas razões. A primeira delas é que o número de estudantes nelas era diverso: quando os grupos focais foram aplicados, a mais nova possuía 25 alunos matriculados, enquanto a mais antiga tinha apenas 15. Logo, para ter uma amostra significativa de participantes da turma de calouros, era preciso que mais deles fossem ouvidos. O outro motivo foi o fato de que, durante a condução do primeiro grupo focal com os calouros, os próprios sujeitos terem explicitamente dito que todos os presentes eram somente os mais proficientes na LE. Foi, então, necessário fazer mais uma sessão para que aqueles que menos dominavam o idioma também tivessem a oportunidade de ter sua voz inclusa no nosso estudo.

\section{Aplicação de grupo focal}

Os passos que sugerimos que sejam seguidos para a aplicação de um grupo focal são semelhantes aos itens do guia de condução de sessão, com o acréscimo de mais alguns:

- Organizar o ambiente;

- Acolher dos sujeitos;

- Convidar um auxiliar de pesquisa;

- Convidar os participantes;

- Explanar sobre a técnica;

- Ler e assinar o TCLE;

- Apresentar os participantes;

- Discutir as questões;

- Sintetizar a discussão;

- Organizar e guardar materiais utilizados.

Façamos algumas considerações sobre cada um deles. O ideal é que organizar o ambiente seja a primeira coisa a ser feita. Isso envolve: ordenar as carteiras/cadeiras para participantes e pesquisador, dispor e ligar os recursos multimídia para a gravação de modo 
que todos os envolvidos possam ser filmados e, no nosso caso, também incluiu acomodar um lanche que servimos aos alunos na etapa a seguir.

Bem acolher os sujeitos é essencial para a motivação e um bom início de construção de relação entre população-amostra e pesquisador, principalmente quando se trata de pesquisa sem compensação financeira para o participante e, ainda mais, na investigação sobre crenças, pois é necessário que os indivíduos sintam-se à vontade e confiem suficientemente em quem conduzirá o grupo focal para expressar suas emoções, medos, anseios, opiniões etc. sem receios. Em nosso estudo, fizemos esse acolhimento por meio de um lanche que foi servido aos alunos como em um momento de confraternização, uma refeição simples com bolo, biscoitos, pipoca e refrigerante, que foi conveniente para o horário em que as sessões foram realizadas por volta das dez horas da manhã.

Enquanto os sujeitos lanchavam, perguntamos a cada participante se preferiam usar seu próprio nome ou um pseudônimo, fizemos uma plaquinha com o nome/pseudônimo de cada um e colocamos nas carteiras de modo que ficasse visível na filmagem. As plaquinhas foram confeccionadas com papel A4 e marcador para quadro branco com letras grandes.

Ainda durante o lanche, tratamos de convidar um auxiliar de pesquisa para cuidar da gravação em áudio e vídeo. Ele(a) foi escolhido por indicação dos demais alunos da turma como alguém que sabia manusear com destreza os recursos multimídia e, ao final, oferecemos-lhe uma declaração de participação. Não existe uma obrigatoriedade de utilizar um auxiliar, mas é recomendável, pois permite que o entrevistador foque a sua atenção apenas em conduzir o grupo focal, o que já é suficientemente trabalhoso e desgastante, além de diminuir os riscos de problemas com a gravação, uma vez que haverá uma pessoa cuidando somente disso o tempo inteiro.

Há diversas maneiras de selecionar alguns indivíduos de um grupo para participar. Pode ser feito sorteio, escolha com base em características específicas (ex.: idade, sexo, experiência, profissão etc.), entre outras alternativas. Em nosso estudo, preferimos que a participação fosse voluntária e explicamos aos sujeitos que não gostaríamos de escolher os 
participantes, mas que aqueles que desejassem participar se manifestassem espontaneamente. Em todas as sessões pelo menos seis alunos escolheram ficar. Nossa opção de apenas convidar os participantes foi possível porque a população-amostra, em geral, tinha um perfil bastante semelhante e que, portanto, não influenciaria na construção de suas crenças.

O próximo passo foi explanar sobre a técnica. Nesse momento: demos boas-vindas aos sujeitos e agradecemos a sua participação, apresentamos e esclarecemos as funções da moderadora e do(a) auxiliar de pesquisa, explanamos sobre a investigação e a sua importância, explicamos o que é e para que serve um grupo focal, orientamos sobre a dinâmica do trabalho, expomos o tema focal da sessão, apontamos brevemente os tópicos a serem discutidos (de acordo com o temário), dissemos que os tópicos não eram fechados e que os participantes poderiam sugerir ainda outros que considerassem relevantes, contanto que dentro do mesmo tema. A orientação sobre a dinâmica de trabalho consistiu em assinalar a importância de todos participarem, evitar as conversas paralelas e dispersões, deixar sua plaquinha sempre à mostra, ao dirigir a palavra a um colega usar o nome escrito na plaquinha, não interromper a fala do outro, respeitar opiniões divergentes etc.

Passamos, então, para o momento de ler e assinar o TCLE, além de abrir espaço para esclarecer alguma possível dúvida sobre os termos do documento. Logo após, iniciamos a gravação e passamos a apresentar os participantes. Cada um deles identificou-se conforme o nome/pseudônimo escolhido. Nessa etapa enfatizamos que é importante avisar aos sujeitos o momento em que a começar a gravar, bem como o seu fim.

Para discutir as questões é necessário que o pesquisador tenha sempre em mãos o temário ou guia de temas e tome nota por escrito de qualquer ocorrência relevante para a investigação. Quando o estudo implicar em fazer as mesmas perguntas em mais de uma sessão de grupo focal, como no nosso, sugerimos que elas sejam feitas na mesma ordem e lidas para evitar que a sua disposição ou formulação interfiram nas respostas dos indivíduos. 
Recomendamos não encerrar abruptamente após a última pergunta, mas sintetizar a discussão retomando os tópicos discutidos e com base nas notas tomadas, além de perguntar se qualquer participante tem mais alguma consideração a fazer, agradecer a participação de todos e, somente então, finalizar a gravação.

Ao final, será necessário organizar e guardar os materiais utilizados. Para tanto, verifique se todos assinaram e receberam uma cópia do TCLE, se as gravações em áudio e em vídeo foram devidamente salvas e, se possível, salve-as em mais de um formato e faça back-up para um pen-drive e/ou nuvem evitando que sejam perdidas.

\section{Considerações finais}

Cremos que alcançamos o nosso objetivo inicial de construir um texto que servisse para auxiliar no planejamento e aplicação de grupos focais sobre crenças no EA de idiomas, pois apresentamos aqui diretrizes que podem ser seguidas por interessados que pretendam usar o grupo focal em suas próprias pesquisas sobre o mesmo tema.

Respondemos também às nossas quatro perguntas norteadoras:

- Quais as vantagens de usar grupo focal em pesquisas sobre crenças?

Revela uma variedade de opiniões sobre um determinado tópico; ajuda a esclarecer ou validar informação recolhida através de entrevistas individuais, pesquisa ou outros métodos de recolha de dados; pode conduzir a novas informações importantes tanto para os facilitadores quanto para o grupo de participantes; é agradável para os participantes; tem baixo custo; fornece resultados rápidos; possui formato flexível; é eficiente para obter informações qualitativas e para esclarecer questões complexas no desenvolvimento de projetos; além de ser adequado para medir o grau de satisfação das pessoas envolvidas.

- Quais as desvantagens de usar grupo focal em pesquisas sobre crenças?

Seu formato flexível o torna susceptível à maneira de ser do moderador; não fornece dados quantitativos; as informações obtidas não podem ser generalizadas e podem ser difíceis de serem analisadas; não garante total anonimato; exige facilitador/moderador com experiência em conduzir grupos; depende da seleção criteriosa dos participantes; as discussões podem ser desviadas ou dominadas por poucas pessoas; os comentários devem ser 
interpretados no contexto do grupo; apresenta um desafio logístico; exige um moderador habilidoso; e há menos controle sobre a coleta de dados.

- Como planejar um grupo focal para desenvolver uma pesquisa sobre crenças?

Durante o planejamento é necessário elaborar três documentos (TCLE, guia de condução de sessão e temário ou guia de temas), escolher e testar recursos de gravação em áudio e vídeo, determinar a quantidade de participantes por sessão e definir a quantidade de sessões.

- Como aplicar um grupo focal para desenvolver uma pesquisa sobre crenças?

A aplicação envolve organizar o ambiente, acolher dos sujeitos, convidar auxiliar de pesquisa, convidar os participantes, explanar sobre a técnica, ler e assinar o TCLE, apresentar os participantes, discutir as questões, sintetizar a discussão e, por fim, organizar e guardar os materiais utilizados.

Ao final do presente artigo, resultados apontam que, apesar das vantagens e desvantagens implicadas, é possível utilizar o grupo focal para produzir dados sobre crenças a respeito do EA de LE, mas que, para tanto, é preciso que o pesquisador, antecipadamente, prepare-se e planeje a sua execução de maneira adequada.

\title{
BELIEFS IN THE TEACHING AND LEARNING OF LANGUAGES: THE FOCUS GROUP AS AN INSTRUMENT OF DATA PRODUCTION
}

\begin{abstract}
The subject investigated was the focus group as a tool of data production in studies about beliefs in teaching and learning of foreign languages. Our intention was to assist in the planning and application of focus groups that deal with this theme. We conducted a bibliographic study and report our own experience in planning and applying the instrument. The theoretical framework included Barbosa (2012), Backes et al (2011), Kinoshita (2018), Morgan (2013), Santos, Silva and Jesus (2016), Teixeira and Maciel (2009), Trad (2009), among others. Results indicated that the use of the focus group is appropriate to produce data about beliefs regarding the teaching and learning of languages, as long as the researcher involved plans and prepares in advance and appropriately.
\end{abstract}

KEYWORDS: Beliefs; Focus group; Language teaching-learning.

\section{REFERÊNCIAS}

ASCHIDAMINI, I.M.; SAUPE, R. Grupo focal - estratégia metodológica qualitativa: um ensaio teórico. Cogitare Enfermagem, Curitiba, v. 9, n. 1, p. 9-14, 2004. 
KINOSHITA, L. Crenças e expectativas sobre ensinar/ aprender a ser professor de lingua estrangeira (Representações de graduandos, formadores e agentes governamentais: o caso da formação docente inicial na Unifesspa). 2018. 774 f. Tese (Doutorado em Educação) - Faculdade de Educação, Universidade de São Paulo, São Paulo, 2018.

BACKES, D.S. et al. Grupo focal como técnica de coleta e análise de dados em pesquisas qualitativas. O Mundo da Saúde, São Paulo, v. 35, n. 4, p. 438-442, 2011.

BARBOSA, J.A.G. A utilização do Grupo Focal como método de coleta dados em pesquisa qualitativa na saúde e na enfermagem. Periódico Científico do Núcleo de Biociências, Belo Horizonte, v. 02, n. 03, p. 38-46, ago./set. 2012.

BARCELOS, A.M.F. Reflexões acerca da mudança de crenças sobre ensino e aprendizagem de línguas. Revista Brasileira de Linguística Aplicada, v. 7, n. 2, p. 109-138, 2007.

. Metodologia de pesquisa das crenças sobre a aprendizagem de línguas: estado da arte. Revista Brasileira de Linguística Aplicada, v. 1, n. 1, p. 71-92, 2001.

DIAS, C.A. Grupo focal: técnica de coleta de dados em pesquisas qualitativas. Informação \& Sociedade, v.10, n.2, 2000.

DICICCO-BLOOM, B.; CRABTREE, B.F. The qualitative research interview. Medical Education, v. 40, n. 4, p. 314-321, abr. 2006.

DÖRNYEI, Z. Motivation in second language learning. In: CELCE-MURCIA, M.;

BRINTON, D.M.; SNOW, M.A. (Eds.). Teaching English as a second or foreign language. 4. ed., Boston: National Geographic Learning/Cengage Learning, 2014. p. 518-531.

GIBBS, A. Focus groups. Guildford: University of Surrey, 1997. Disponível em: http://sru.soc.surrey.ac.uk/SRU19.html. Acesso em: 13 mai. 2020.

GOMES, M.E.S.; BARBOSA, E.F. A técnica de grupos focais para obtenção de dados qualitativos. Educativa - Instituto de Pesquisas e Inovações Educacionais, fev. 1999.

I-TECH. Organizar e conduzir grupos focais: um guião de implementação técnica. Seattle: US Department of Health and Human Services Health Resources and Services Agency, 2008.

KIND, L. Notas para o trabalho com a técnica de grupos focais. Psicologia em Revista, Belo Horizonte, v. 10, n. 15, p. 124-136, jun. 2004.

LARSEN-FREEMAN, D. Chaos/complexity science and second language acquisition. Applied Linguistics. Oxford: Oxford University Press, v. 2, n. 18, p.141-165, 1997.

MASI, B. Customers in focus: a guide to conducting and planning focus groups. Seattle: The Simply Better! Team, s/d.

MORGAN, D.L. Focus groups as qualitative research: planning and research design for focus groups. London: Sage Publications/ Thousand Oaks, 2013. 
Oaks, 1997.

Focus groups as qualitative research. 2. ed., London: Sage Publications / Thousand

OLIVEIRA, A.A.R; LEITE, C.A.P.F; RODRIGUES, C.M.C. O processo de construção dos grupos focais na pesquisa qualitativa e suas exigências metodológicas. In: CONGRESSO DA ANPAD, 31., 2007, Rio de Janeiro. Anais... Rio de Janeiro, 2007. p. 1-15.

PAIVA, V.L.M.O. Caleisdoscópio: fractais de uma oficina de ensino aprendizagem. Memorial. UFMG, 2002.

PAJARES, M. F. Teachers' beliefs and educational research: cleaning up a messy construct. Review of Educational Research, v. 62, n. 3, p. 307-332, 1992.

SANTOS, R.C.S.; SILVA, A.C.T.; JESUS, M.P. O grupo focal como técnica de coletas de dados na pesquisa em educação: aspectos éticos e epistemológicos. In: ENCONTRO INTERNACIONAL DE FORMAÇÃO DE PROFESSORES, 9., 2016. Anais... Aracaju, 2016.

SILVA, J.R.S.; ASSIS, S.M.B. Grupo focal e análise de conteúdo como estratégia metodológica clínica-qualitativa em pesquisas nos distúrbios do desenvolvimento. Cadernos de PósGraduação em Distúrbios do Desenvolvimento, São Paulo, v.10, n.1, p.146-152, 2010.

TEIXEIRA, S.R.; MACIEL, M.D. Grupo focal: Técnica de coleta de dados e espaço de formação docente. In: ENCONTRO NACIONAL DE PESQUISA EM EDUCAÇÃO EM CIÊNCIAS, 7., 2009, Florianópolis. Anais... Florianópolis, 2009.

TRAD, L.A.B. Grupos focais: conceitos, procedimentos e reflexões baseadas em experiências com o uso da técnica em pesquisas de saúde. Physis, Rio de Janeiro, v. 19, n. 3, p. 777-796, 2009.

VILLARD, J.A. Use of focus groups: an effective tool for involving people in measuring quality and impact. Obio State University Papers, v. 7, n. 6, 2003.

ZIMMERMANN, M.H.; MARTINS, P.L.O. Grupo focal na pesquisa qualitativa: relato de experiência. In: CONGRESSO NACIONAL DE EDUCAÇÃO, 8., 2008, Curitiba. Anais... Curitiba, 2008. p. 12115-12125.

Recebido em: 18/05/2020.

Aprovado em: 04/06/2020. 